Fayoum Journal of Agricultural Research
and Development
ISSN:1110-7790

\title{
Influence of potassium humate and calcium phosphate on production of pepper seedlings
}

\author{
Tarek A. El-Masry, Nevein A. H. El-Sawah*, Ashraf Sh. Osman, Sara R. Abd El- \\ Ghany and Gehan S. M. Abed El-Hamed \\ Horticulture Department, Faculty of Agriculture, Fayoum University, 63514 Fayoum, \\ Egypt
}

\section{ABSTRACT}

Two shadow net house experiments were conducted during 2018 and 2019 in a private Nursery, Ibshawy district, Fayoum, Egypt, to study the effect of potassium humate and calcium phosphate on morphological characters, membrane permeability (RWC and MSI), leaf photosynthetic pigments and leaf elemental contents of pepper transplants. The experimental design used was a split-plot in randomized complete blocks with four replications. Potassium humate levels $\left(0\right.$ and $\left.0.5 \mathrm{~g}^{\text {litre-medium }}{ }^{-1}\right)$ were distributed in the main plots, while calcium phosphate concentrations $(0,100,200,400,600,800$ and $1000 \mathrm{mg}$ litre-water ${ }^{-1}$ ) were randomly allocated to the sub-plots. Growing medium provided with 0.5 $\mathrm{g}^{-1}$ potassium humate gave the highest significant values on morphological characters, membrane permeability, leaf photosynthetic pigments and leaf $\mathrm{N}, \mathrm{P}, \mathrm{k}$ and $\mathrm{Ca}$ contents as compared to growing medium without potassium humate treatment during both seasons. However, number of leaves transplant ${ }^{-1}$ was not significantly affected. Generally, foliar application of calcium phosphate at 600 and $800 \mathrm{mg} \mathrm{l}^{-1}$ was significantly recorded higher mean values of morphological characters, membrane permeability and leaf photosynthetic pigments as compared to other concentrations but number of leaves $\operatorname{transplant}^{-1}$ was not significantly affected. While, spraying calcium phosphate at $100 \mathrm{mg} \mathrm{l}^{-1}$ significantly recorded higher mean values of leaf $\mathrm{N}$ content. Application of calcium phosphate at $1000 \mathrm{mg} \mathrm{l}^{-1}$, significantly, attained higher values of leaf $\mathrm{P}$ and $\mathrm{Ca}$ content. Whilst application of calcium phosphate 200 or $400 \mathrm{mg} \mathrm{l}^{-1}$ gave the highest significant values on leaf $\mathrm{K}$ content, in both seasons of 2018 and 2019. These results recommend using the growth medium supplemented with $0.5 \mathrm{~g} \mathrm{l}^{-1}$ potassium humate in integration with calcium phosphate at 600 and $800 \mathrm{mg} \mathrm{l}^{-1}$ act to enhancing the plant physio-biochemical components, which reflected in high growth of pepper seedlings.

\section{KEYWORDS}

Pepper (Capsicum annuum L.), Potassium humate, Calcium phosphate, Morphological characters, Membrane permeability (RWC and MIS), Leaf photosynthetic pigments, Leaf N, $P, K$ and Ca contents.

\footnotetext{
* Corresponding author: nas03@fayoum.edu.eg
}

Received: 6/4/ 2021, Accepted: 20/4/ 2021 


\section{INTRODUCTION}

Seedling production in general has become a large industry in all countries of the world. The most important problems is slow growth in cold weather due to low of phosphorus absorption mainly, which affects the growth of seedlings. It is also important for the seedling producer to obtain strong and hardening seedlings to withstand the different environmental conditions when they are grown in the field. The growth media supplemented with humic acid has been shown to have beneficial influences on plant growth (Türkmen et al., 2004) and on the physical characteristics of growing media in Styrofoam flats in which soils or growing media tend to become compacted. Compaction is often accompanied by a decrease in water-holding capacity, drainage, aeration, the rate of water infiltration, and root penetration. The major functional groups in humic acid include carboxyl, phenolic hydroxyl, alcoholic hydroxyl, ketone, and quinoid moieties (Russo and Berlyn, 1990). The benefits of humic acid for plant growth may be related to its positive effects on increased fertilizeruse efficiency and/or reduced medium compaction of the growing medium (Nardi et al., 2002). Also, humic acid has been claimed to promote plant growth by increasing cell membrane permeability, oxygen uptake, respiration and photosynthesis, nutrient uptake, and root cell elongation (Russo and Berlyn, 1990 and Nardi et al., 2002). The influences of humic acid on the growth of tomato seedlings have been investigated in some growing media (Jindo et al., 2011; Osman and Rady, 2014; Rady et al., 2018b and ColpasCastillo et al., 2018).
Buddhy (2014) explained that the phosphorus, one of the seventeen elements nutrients required for plant growth and reproduction, is often indicated to as the energizer since it helps store and transfer energy during photosynthesis. It is also part of the genetic material of all cells-DNA and RNA. All plants require phosphorus during periods of rapid growth. Most annual plants require large amounts of phosphorus as they begin to grow. Plants grown in cold weather which have limited roots and rapid top growth, such as pepper transplants produced, are high phosphorus users. Phosphorus absorption is reduced at low soil temperatures less than $13^{\circ} \mathrm{C}$. Phosphorus is necessary to stimulate early root formation and growth, so it is necessary for the growth of seedlings roots in general, give hardiness to seedling, and promote vigorous start (cell division) to plants. Phosphorus has a role in hydrogen, oxygen, fat, and carbon metabolism, in photosynthesis, and in respiration. Upadhyaya (2017) mentioned that the calcium is an essential plant nutrient. It plays many important role in plant like, participate in the metabolic process of another nutrient uptake, promotes proper plant cell elongation, strengthen cell wall, and participate in an enzymatic and hormonal process. In addition, the adequate level of $\mathrm{Ca}_{2}^{+}$is required in the external medium to maintain the selectivity and integrity of cell membrane.

Accordingly, the present work was designed with the objective to evaluate the potential beneficial effects of potassium humate and/or calcium phosphate on growth, leaf photosynthetic pigments and nutrients, of pepper seedling produced. The study also aimed to establish a relationship between the positive changes in the contents of leaf photosynthetic pigments and nutrients; $\mathrm{N}, \mathrm{P}, \mathrm{K}$ and $\mathrm{Ca}$ and the 
improvement in transplant performance in growing medium.

\section{MATERIALS AND METHODS} Source, physical and chemical properties of potassium humate and calcium phosphate

The physical and chemical characteristics of potassium humate according to published procedures (Humintech $\mathrm{GmbH}, \mathrm{Am}$ Pösenberg 9-13 • D 41517 Grevenbroich, Germany, https://www.humintech.com/agriculture/pro ducts/powhumus-wsg-85) are presented in Table 1. Calcium phosphate $\mathrm{Ca}\left(\mathrm{H}_{2} \mathrm{PO}_{4}\right)_{2}$ produced by Hopkin \& Williams Ltd, chemical manufacturers (St Davids Court, Union Street, Wolverhampton, West Midlands, United Kingdom, WV1 3JE).

Table 1. Physical and chemical characteristics of potassium humate.

\begin{tabular}{lc}
\hline \multicolumn{2}{c}{ Properties } \\
\hline Appearance & Water soluble granules \\
Potassium humates $(\%)$ & $80-85$ \\
Humic acids (ISO 19822) $(\%)$ & 65 \\
Hydrophobic fulvic acids (ISO 19822) $(\%)$ & 6 \\
Potassium $\left(\mathrm{K}_{2} \mathrm{O}\right)(\%)$ & $10-12$ \\
Dry substance $(\%)$ & $85-90$ \\
Fe $(\%)$ & 1.0 \\
Other minerals $(\%)$ & 2.0 \\
Particle size of insoluble constituents $(\mu \mathrm{m})$ & $<100$ \\
Solubility in Water $(\%)$ & 100 \\
Bulk density $\left(\mathrm{kg} \mathrm{l}^{-1}\right)$ & 0.60 \\
pH & $9-10$ \\
CEC (meq $\left.100 \mathrm{~g}^{-1}\right)$ & $400-600$ \\
\hline
\end{tabular}

\section{Composition of the growing medium}

Coco peat, and vermiculite $(1: 1 \mathrm{v} / \mathrm{v})$, were mixed with a fertilizer consisting of with $300 \mathrm{~g}$ ammonium nitrate $(33.5 \% \mathrm{~N})$, $400 \mathrm{~g}$ calcium superphosphate $\left(15 \% \mathrm{P}_{2} \mathrm{O}_{5}\right)$, $150 \mathrm{~g}$ potassium sulphate $\left(48 \% \mathrm{~K}_{2} \mathrm{O}\right), 50 \mathrm{~g}$ micro-nutrient solution and $75 \mathrm{~g}$ of Moncut SC $[\mathrm{a} 25 \% \quad(\mathrm{w} / \mathrm{w})$ active flutolanilcontaining, wettable powder, fungicide] for each $601^{-1}$ of the mixture.

\section{Experimental layout}

Two shadow net house trials were conducted during 2018 and 2019 in a private Nursery, Ibshawy district, Fayoum, Egypt. Treatments comprised of growth medium without and with $0.5 \mathrm{~g}$ litre-medium ${ }^{-1}$ potassium humate mixed while preparing the growing medium (this level of potassium humate gave the best results among several levels that were examined in preliminary studies on pepper transplants produced - data not shown - and were therefore selected for this study), and seven concentrations of calcium phosphate; $0,100,200,400,600$, 800 and 1000 mg litre-water ${ }^{-1}$ was applied as foliar application to run-off, three times; 25, 35 and 45 days after sowing. Few drops of salient film were added to the spraying solution as a wetting agent. The Styrofoam flats $(\mathrm{n}=56$ for all treatments) were arranged in a split-plot in randomized complete blocks with four replications (each tray was one replicate). Main plots consisted of potassium humate with two levels, while sub-plots were allocated to calcium phosphate concentrations. Individual 209cell Styrofoam flats $(2.6 \mathrm{~cm} 2.6 \mathrm{~cm} 7.0 \mathrm{~cm}$; $25 \mathrm{~cm}^{3}$ per inverted pyramid cell; Speedling, El-Amryya, Alexandria, Egypt) were sown (one seed per cell) with imported pepper seeds (Capsicum annuum. 'Omega' F1 Hybrid, Country of Origin: China, importer 
Kanze Group For Projects Developments and Services, Egypt) on February 11, 2018 and February 12, 2019. The average temperature during this period was $19 \pm 3{ }^{\circ} \mathrm{C}$ during the day and $9 \pm 2{ }^{\circ} \mathrm{C}$ at night, and the relative humidity ranged from $70-75 \%$, and natural day-length ranged from 11-12 $\mathrm{h}$. The trays were rotated daily within each block to avoid any positional bias. All pepper

\section{Data Recorded}

\section{Assessment of morphological}

characters: Fifty-five days old pepper seedling were removed at random from the four replicate Styrofoam flats of each medium (i.e., ten transplants from each flat) and dipped in a bucket filled with water. The pepper seedling were moved smoothly to remove any adhering particles of medium. The transplants were then separated into leaves, stems, and roots to measure stem length $(\mathrm{cm})$; measured starting from the growing medium level to the apical meristem of the main stem. Stem diameter (mm); measured by using Sealy So707-Digital Electronic Vernier Caliper 0-150 mm/0-6" at growing medium level. Root, leaves and stem dry weight transplant $^{-1}(\mathrm{~g})$; placed in an oven at $70^{\circ} \mathrm{C}$ to reach a constant dry weight which was

Membrane permeability: Leaf samples for membrane permeability measurements, were collected from five randomly selected transplants in each experimental unit, after 70 days from culturing date, were collected, washed with tap water, rinsed three times with distilled water to measure; relative water content (RWC \%); determined using the formula of Hayat et al. (2007) and membrane stability index (MSI \%); estimated as described by Sairam (1994). Leaf photosynthetic pigments content: Leaf chlorophyll a, b, and carotenoid contents were determined using the dimethyl seedling were grown for 55 days. Seedlings were overhead-irrigated daily and foliar application after 27 and 40 days of sowing with a fertilizer 20:20:20 NPK $4 \mathrm{~g} \mathrm{l}^{-1}$ water. As well as pests control were performed whenever it was necessary and as recommended in the commercial production of pepper transplants

recorded in each case. Total dry weight transplant $^{-1}(\mathrm{~g})$; mathematically calculated by summation oven dried roots, leaves and shoots transplant ${ }^{-1}$. Number of leaves transplant $^{-1}$. Leaf area transplant ${ }^{-1}(\mathrm{~cm})$; measured using leaf area-leaf weight relationship as illustrated by Taha and Osman (2018). Leaf area transplant ${ }^{-1}$ was calculated using the following formula: Leaf area transplant ${ }^{-1}=\frac{(L D W)}{(D D W)} \times \mathrm{DA}$ where LDW is the total leaf dry weight (g), DDW is the disks dry weight and DA is the discs area. Leaf area leaf ${ }^{-1}(\mathrm{~cm})$; calculated using the following formula:

leaf
are
a
leaf
$-1=$

formamide (DMF) method were measured and calculated according to Moran and Porath, 1980 and Wellburn, 1994.

Leaf nutrient contents: Leaf samples from seven randomly selected transplants, in each experimental unit, were collected, washed with tap water, rinsed three times with distilled water and dried at $70^{\circ} \mathrm{C}$ in a forcedair oven till constant weight to measure: leaf $\mathrm{N}$ (mg g $\left.{ }^{-1} \mathrm{DW}\right)$; colorimetrically determined by using the technique of $\mathbf{H a f e z}$ and Mikkelsen (1981). Leaf $\mathrm{P}$ (mg $\left.\mathrm{g}^{-1} \mathrm{DW}\right)$; colorimetrically estimated according to the stannous molybdate chloride method as 
illustrated in A. O. A. C (1995). Leaf K (mg $\mathrm{g}^{-1} \mathrm{DW}$ ); photometrically measured using Flame photometer as mentioned by Wilde $\boldsymbol{e t}$ al. (1985). Leaf $\mathrm{Ca}\left(\mathrm{mg} \mathrm{g}^{-1} \mathrm{DW}\right)$; was determined using a Perkin-Elmer Model 3300 Atomic Absorption Spectrophotometer (Chapman and Pratt, 1961).

Statistical analysis

All data were subjected to analysis of variance (ANOVA) for a split-plot system in

\section{RESULTS AND DISCUSION}

\section{Morphological Characters}

The growth medium supplemented with $0.5 \mathrm{~g} \mathrm{l}^{-1}$ potassium humate gave the highest significant values on all vegetative growth parameters; stem length and diameter, roots, a randomized complete blocks design, after testing for homogeneity of error variances according to the procedure outlined by Gomez and Gomez (1984) using InfoStat software estadistico (2016). Significant differences between treatments were compared at $\mathrm{P} \leq 0.05$ by Duncan's multiple range test.

leaves, stem and total transplant dry weight transplant ${ }^{-1}$, leaf area transplant ${ }^{-1}$ and leaf area leaf ${ }^{-1}$ of pepper seedlings as compared to the control treatment. Except number of leaves transplant ${ }^{-1}$, which was not significantly affected during the two successive seasons.

Table 2. Effect of potassium humate-supplemented medium and calcium phosphate on stem length and diameter transplant ${ }^{-1}$ of pepper seedlings.

\begin{tabular}{|c|c|c|c|c|c|}
\hline \multicolumn{2}{|c|}{ Treatment } & \multirow{2}{*}{\multicolumn{2}{|c|}{$\begin{array}{l}\text { Stem length } \\
(\mathrm{cm})\end{array}$}} & \multirow{2}{*}{\multicolumn{2}{|c|}{$\underset{(\mathrm{mm})}{\operatorname{Stem} \text { diameter }}$}} \\
\hline \multirow{2}{*}{$\begin{array}{c}\text { Potassium } \\
\text { humate } \\
\left({\left.\mathrm{g} \mathbf{l}^{-1}\right)}^{-1}\right.\end{array}$} & \multirow{2}{*}{$\begin{array}{c}\text { Calcium } \\
\text { Phosphate } \\
\left(\mathrm{mg} \mathrm{l}^{-1}\right)\end{array}$} & & & & \\
\hline & & 2018 & 2019 & 2018 & 2019 \\
\hline \multirow[t]{2}{*}{$\begin{array}{c}\mathbf{0} \\
\mathbf{0 . 5}\end{array}$} & & $\begin{array}{l}13.2^{\mathrm{B} *} \\
14.6 \mathrm{~A}\end{array}$ & $\begin{array}{l}12.5^{\mathrm{B}} \\
13.8^{\mathrm{A}}\end{array}$ & $\begin{array}{l}2.60^{\mathrm{B}} \\
2.85^{\mathrm{A}}\end{array}$ & $\begin{array}{l}2.54^{\mathrm{B}} \\
2.80^{\mathrm{A}} \\
\end{array}$ \\
\hline & \begin{tabular}{|c|} 
o \\
100 \\
200 \\
400 \\
600 \\
800 \\
$\mathbf{8 0 0}$ \\
1000 \\
\end{tabular} & $\begin{array}{l}11.0^{\mathrm{D}} \\
12.6^{\mathrm{C}} \\
12.8^{\mathrm{C}} \\
13.8^{\mathrm{B}} \\
16.4^{\mathrm{A}} \\
16.6^{\mathrm{A}} \\
14.0^{\mathrm{B}}\end{array}$ & $\begin{array}{l}9.7^{\mathrm{E}} \\
11.6^{\mathrm{D}} \\
12.8^{\mathrm{C}} \\
13.0^{\mathrm{C}} \\
15.6^{\mathrm{A}} \\
15.9^{\mathrm{A}} \\
13.7^{\mathrm{B}}\end{array}$ & $\begin{array}{l}2.61 \mathrm{~B} \\
2.67 \mathrm{~B} \\
2.67 \mathrm{~B} \\
2.68 \mathrm{~B} \\
2.85 \mathrm{~A} \\
2.88 \mathrm{~A} \\
2.72 \mathrm{~B} \\
\end{array}$ & $\begin{array}{l}2.43 \mathrm{C} \\
2.49 \mathrm{C} \\
2.66 \mathrm{~B} \\
2.71 \mathrm{~B} \\
2.81 \mathrm{~A} \\
2.89 \mathrm{~A} \\
2.69 \mathrm{~B} \\
\end{array}$ \\
\hline $\mathbf{0}$ & $\begin{array}{c}\text { o } \\
100 \\
200 \\
400 \\
600 \\
\text { 800 } \\
1000 \\
\end{array}$ & $\begin{array}{l}10.4^{\mathrm{g}} \\
12.0^{\text {ef }} \\
12.2^{\mathrm{e}} \\
13.0^{\mathrm{d}} \\
15.5^{\mathrm{b}} \\
15.7^{\mathrm{b}} \\
13.3^{\mathrm{d}}\end{array}$ & $\begin{array}{l}9.3 \mathrm{i}^{\mathrm{g}} \\
11 . \mathrm{g}^{\mathrm{g}} \\
12.1^{\mathrm{f}} \\
12.3^{\mathrm{f}} \\
14.7^{\mathrm{bc}} \\
15.1^{\mathrm{b}} \\
13.2^{\mathrm{e}}\end{array}$ & $\begin{array}{l}2.51 \mathrm{e} \\
2.56 \mathrm{de} \\
2.52 \mathrm{e} \\
2.53 \mathrm{e} \\
2.70 \mathrm{bcd} \\
2.74 \mathrm{bc} \\
2.62^{\mathrm{cde}}\end{array}$ & $\begin{array}{l}2.34^{\mathrm{f}} \\
2.38^{\mathrm{f}} \\
2.54^{\mathrm{e}} \\
2.57^{\mathrm{e}} \\
2.64^{\mathrm{de}} \\
2.73^{\mathrm{cd}} \\
2.58^{\mathrm{e}}\end{array}$ \\
\hline 0.5 & $\begin{array}{c}\text { o } \\
100 \\
200 \\
400 \\
600 \\
800 \\
\mathbf{1 0 0 0}\end{array}$ & $\begin{array}{l}11.5^{\mathrm{f}} \\
13.2^{\mathrm{d}} \\
13.4^{\mathrm{d}} \\
14.6^{\mathrm{c}} \\
17.3^{\mathrm{a}} \\
17.4^{\mathrm{a}} \\
14.7^{\mathrm{c}}\end{array}$ & $\begin{array}{l}10.2^{\mathrm{h}} \\
12.2^{\mathrm{f}} \\
13.4^{\mathrm{e}} \\
13.7^{\mathrm{de}} \\
16.5^{\mathrm{a}} \\
16.8^{\mathrm{a}} \\
14.2^{\mathrm{cd}}\end{array}$ & $\begin{array}{l}2.71^{\mathrm{bcd}} \\
2.77^{\mathrm{bc}} \\
2.82^{\mathrm{b}} \\
2.82^{\mathrm{b}} \\
3.00^{\mathrm{a}} \\
3.03^{\mathrm{a}} \\
2.82^{\mathrm{b}}\end{array}$ & $\begin{array}{l}2.52^{\mathrm{e}} \\
2.60^{\mathrm{de}} \\
2.77^{\mathrm{c}} \\
2.85^{\mathrm{bc}} \\
2.97^{\mathrm{ab}} \\
3.05^{\mathrm{a}} \\
2.81^{\mathrm{c}}\end{array}$ \\
\hline & & 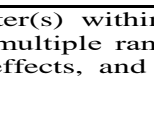 & & inter & $\begin{array}{l}\text { effects ar } \\
\text { ase letter(s) }\end{array}$ \\
\hline
\end{tabular}


Generally, foliar application of calcium phosphate at concentrations of 600 and 800 mg $1^{-1}$ was superior and significantly recorded higher mean values of stem length, diameter transplant ${ }^{-1}$, leaves, stem and total transplant dry weight transplant ${ }^{-1}$, leaf area transplant $^{-1}$ and leaf area leaf ${ }^{-1}$ of pepper seedlings compared to the other concentrations of calcium phosphate in both years. While, increasing calcium phosphate concentration from 0 to $1000 \mathrm{mg}^{-1}$ increased roots dry weight transplant ${ }^{-1}$, during the two successive seasons. Except number of leaves transplant ${ }^{-1}$, which was not significantly affected, in both experimental seasons. Generally, the combined medium supplemented with $0.5 \mathrm{gl}^{-1}$ potassium humate together with foliar application of calcium phosphate 600 and $800 \mathrm{mg} \mathrm{l}^{-1}$, gave the highest significant values of stem length, diameter transplant ${ }^{-1}$, leaves, stem and total transplant dry weight transplant ${ }^{-1}$, leaf area transplant $^{-1}$ and leaf area leaf ${ }^{-1}$ of pepper seedlings. While, application of calcium phosphate $1000 \mathrm{mg}^{-1}$ together with the medium supplemented with $0.5 \mathrm{~g} \mathrm{l}^{-1}$ potassium humate, significantly achieved the heaviest roots dry weight transplants ${ }^{-1}$. Except number of leaves transplant ${ }^{-1}$, which was not significantly affected, in both experimental seasons which was not significantly affected in both years.

Table 3. Effect of potassium humate-supplemented medium and calcium phosphate on roots, leaves, stem and total transplant dry weight of pepper seedlings.

\begin{tabular}{|c|c|c|c|c|c|c|c|c|c|}
\hline \multicolumn{2}{|c|}{ Treatment } & \multicolumn{8}{|c|}{ Dry weight transplant $^{-1}(\mathrm{~g})$} \\
\hline \multirow{2}{*}{$\begin{array}{c}\text { Potassium } \\
\text { humate } \\
\left(\mathrm{g} \mathrm{I}^{-1}\right) \\
\end{array}$} & \multirow{2}{*}{$\begin{array}{c}\text { Calcium } \\
\text { phosphate } \\
\left(\mathbf{m g ~ ~ ^ { - 1 } )}\right. \\
\end{array}$} & \multicolumn{2}{|c|}{ Roots } & \multicolumn{2}{|c|}{ Leaves } & \multicolumn{2}{|c|}{ Stem } & \multicolumn{2}{|c|}{ Total transplant } \\
\hline & & 2018 & 2019 & 2018 & 2019 & 2018 & 2019 & 2018 & 2019 \\
\hline $\begin{array}{c}0 \\
0.5\end{array}$ & & $\begin{array}{l}0.28^{\text {B* }} \\
0.32^{\text {A }}\end{array}$ & $\begin{array}{l}0.25^{\text {B }} \\
0.28^{\text {A }} \\
\end{array}$ & $\begin{array}{l}0.33^{\mathrm{B}} \\
0.37 \text { A } \\
\end{array}$ & $\begin{array}{l}0.30^{\mathrm{B}} \\
0.33^{\mathrm{A}}\end{array}$ & $\begin{array}{l}0.29^{\mathrm{B}} \\
0.32^{\mathrm{A}}\end{array}$ & $\begin{array}{l}0.26^{\mathrm{B}} \\
0.30^{\mathrm{A}}\end{array}$ & $\begin{array}{l}0.90^{\mathrm{B}} \\
1.01^{\mathrm{A}}\end{array}$ & $\begin{array}{l}0.82^{\text {B }} \\
0.92^{\text {A }} \\
\end{array}$ \\
\hline & $\begin{array}{c}0 \\
100 \\
200 \\
400 \\
600 \\
800 \\
1000\end{array}$ & $\begin{array}{l}0.25^{\mathrm{E}} \\
0.27 \mathrm{D} \\
0.29 \mathrm{C} \\
0.29 \mathrm{C} \\
0.32 \mathrm{~B} \\
0.32^{\mathrm{B}} \\
0.34 \text { A }\end{array}$ & $\begin{array}{l}0.23^{\mathrm{E}} \\
0.24^{\mathrm{E}} \\
0.26^{\mathrm{D}} \\
0.27^{\mathrm{CD}} \\
0.28^{\mathrm{BC}} \\
0.29^{\mathrm{B}} \\
0.31^{\mathrm{A}}\end{array}$ & $\begin{array}{l}0.30^{\mathrm{D}} \\
0.33^{\mathrm{C}} \\
0.34^{\mathrm{B}} \\
0.36^{\mathrm{B}} \\
0.38^{\mathrm{A}} \\
0.39^{\mathrm{A}} \\
0.35^{\mathrm{B}}\end{array}$ & $\begin{array}{l}0.28^{\mathrm{D}} \\
0.29^{\mathrm{CD}} \\
0.31^{\mathrm{C}} \\
0.33^{\mathrm{BC}} \\
0.34^{\mathrm{AB}} \\
0.35^{\mathrm{A}} \\
0.33^{\mathrm{B}}\end{array}$ & $\begin{array}{l}0.24^{\mathrm{F}} \\
0.27^{\mathrm{E}} \\
0.29^{\mathrm{D}} \\
0.31^{\mathrm{C}} \\
0.34^{\mathrm{B}} \\
0.35^{\mathrm{A}} \\
0.32^{\mathrm{BC}}\end{array}$ & $\begin{array}{l}0.23^{\mathrm{E}} \\
0.25^{\mathrm{D}} \\
0.26^{\mathrm{CD}} \\
0.28^{\mathrm{BC}} \\
0.32^{\mathrm{A}} \\
0.32^{\mathrm{A}} \\
0.29^{\mathrm{B}}\end{array}$ & $\begin{array}{l}0.79 \mathrm{G} \\
0.87 \mathrm{~F} \\
0.93 \mathrm{E} \\
0.96 \mathrm{D} \\
1.04 \mathrm{~B} \\
1.07 \mathrm{~A} \\
1.01 \mathrm{C}\end{array}$ & $\begin{array}{l}0.74^{\mathrm{E}} \\
0.78 \mathrm{D} \\
0.82^{\mathrm{C}} \\
0.88^{\mathrm{B}} \\
0.94^{\mathrm{A}} \\
0.96 \mathrm{~A} \\
0.93^{\mathrm{A}}\end{array}$ \\
\hline $\mathbf{0}$ & $\begin{array}{c}\text { 0 } \\
100 \\
200 \\
400 \\
600 \\
800 \\
1000 \\
\end{array}$ & $\begin{array}{l}0.24^{\mathrm{g}} \\
0.26^{\mathrm{f}} \\
0.27^{\mathrm{f}} \\
0.27^{\mathrm{ef}} \\
0.30^{\mathrm{cd}} \\
0.31^{\mathrm{c}} \\
0.32^{\mathrm{c}} \\
\end{array}$ & $\begin{array}{l}0.22^{\mathrm{g}} \\
0.23^{\mathrm{g}} \\
0.24^{\mathrm{fg}} \\
0.25^{\text {ef }} \\
0.27^{\mathrm{de}} \\
0.27^{\mathrm{cde}} \\
0.29^{\mathrm{bcd}} \\
\end{array}$ & $\begin{array}{l}0.28^{\mathrm{g}} \\
0.31^{\mathrm{f}} \\
0.33^{\mathrm{def}} \\
0.34^{\mathrm{cd}} \\
0.36^{\mathrm{bc}} \\
0.38^{\mathrm{b}} \\
0.33^{\mathrm{de}} \\
\end{array}$ & $\begin{array}{l}0.27^{\mathrm{i}} \\
0.28 \mathrm{hi} \\
0.29 \mathrm{ghi} \\
0.31 \text { ef } \\
0.32 \text { de } \\
0.33^{\mathrm{bcd}} \\
0.31 \text { def } \\
\end{array}$ & $\begin{array}{l}0.23^{\mathrm{i}} \\
0.25^{\mathrm{h}} \\
0.27^{\mathrm{gh}} \\
0.29^{\mathrm{fg}} \\
0.32^{\mathrm{cde}} \\
0.34^{\mathrm{bc}} \\
0.30^{\mathrm{ef}} \\
\end{array}$ & $\begin{array}{l}0.21^{\mathrm{h}} \\
0.24^{\mathrm{gh}} \\
0.24^{\mathrm{g}} \\
0.26^{\mathrm{efg}} \\
0.30^{\mathrm{bc}} \\
0.30^{\mathrm{bc}} \\
0.28^{\mathrm{cde}} \\
\end{array}$ & $\begin{array}{l}0.75^{\mathrm{k}} \\
0.82^{\mathrm{j}} \\
0.87^{\mathrm{hi}} \\
0.90^{\mathrm{gh}} \\
0.98^{\mathrm{cde}} \\
1.02^{\mathrm{c}} \\
0.95^{\mathrm{ef}} \\
\end{array}$ & $\begin{array}{l}0.70^{\mathrm{h}} \\
0.74^{\mathrm{g}} \\
0.77^{\mathrm{fg}} \\
0.83^{\mathrm{d}} \\
0.89^{\mathrm{c}} \\
0.91^{\mathrm{bc}} \\
0.88^{\mathrm{c}} \\
\end{array}$ \\
\hline 0.5 & $\begin{array}{c}\text { 0 } \\
100 \\
200 \\
400 \\
600 \\
800 \\
1000\end{array}$ & $\begin{array}{l}0.27^{\mathrm{f}} \\
0.29^{\mathrm{de}} \\
0.31^{\mathrm{c}} \\
0.31^{\mathrm{c}} \\
0.34^{\mathrm{b}} \\
0.34^{\mathrm{b}} \\
0.36^{\mathrm{a}}\end{array}$ & $\begin{array}{l}0.24^{\mathrm{fg}} \\
0.24^{\mathrm{fg}} \\
0.27^{\mathrm{de}} \\
0.29^{\mathrm{bcd}} \\
0.30^{\mathrm{bc}} \\
0.31^{\mathrm{ab}} \\
0.33^{\mathrm{a}}\end{array}$ & $\begin{array}{l}0.31 \text { ef } \\
0.34 \mathrm{~cd} \\
0.36 \mathrm{bc} \\
0.37 \mathrm{~b} \\
0.40 \mathrm{a} \\
0.41 \mathrm{a} \\
0.36 \mathrm{bc}\end{array}$ & $\begin{array}{l}0.30^{\mathrm{fgh}} \\
0.31^{\mathrm{efg}} \\
0.32^{\mathrm{cde}} \\
0.35^{\mathrm{ab}} \\
0.36^{\mathrm{a}} \\
0.36^{\mathrm{a}} \\
0.34^{\mathrm{abc}}\end{array}$ & $\begin{array}{l}0.26^{\mathrm{h}} \\
0.29^{\mathrm{fg}} \\
0.32^{\mathrm{de}} \\
0.34^{\mathrm{bcd}} \\
0.35^{\mathrm{ab}} \\
0.37^{\mathrm{a}} \\
0.34^{\mathrm{b}}\end{array}$ & $\begin{array}{l}0.25^{\mathrm{fg}} \\
0.27^{\mathrm{def}} \\
0.29^{\mathrm{bcd}} \\
0.30^{\mathrm{bc}} \\
0.34^{\mathrm{a}} \\
0.34^{\mathrm{a}} \\
0.31^{\mathrm{b}}\end{array}$ & $\begin{array}{l}0.84^{\mathrm{ij}} \\
0.93^{\mathrm{fg}} \\
0.98^{\mathrm{cde}} \\
1.02^{\mathrm{c}} \\
1.09^{\mathrm{ab}} \\
1.12^{\mathrm{a}} \\
1.06^{\mathrm{b}}\end{array}$ & $\begin{array}{l}0.78^{\text {ef }} \\
0.82^{\text {de }} \\
0.88^{c} \\
0.94^{b} \\
1.00^{a} \\
1.01^{a} \\
0.99^{a}\end{array}$ \\
\hline
\end{tabular}

range test at $\mathrm{P}=0.05$. Uppercase le

The enhancing effect of potassium humate-supplemented medium on morphological characters of pepper transplants compared to potassium humatefree medium (Tables 2 - 4) may be due to ability of potassium humate to form stable complexes with metal ions can be accounted for their high content of oxygen containing functional groups viz., carboxylic, phenolic aliphatic and alcoholic -OH groups (Stevenson et al., 1993). In addition, Türkmen et al. (2004) found that the application of humic acid to growing media has been shown to have enhancing effects on 


plant growth and on the physical
characteristics of growing media in
Styrofoam flats in which soils or growing
media tend to become compacted.
Compaction is often accompanied by
reductions in water-holding capacity,
aeration, drainage, the rate of water
infiltration, and root penetration. In addition,

Jindo et al. (2011) evaluated the application of humic acids stimulated the appearance of root hairs of any plant crops, promoting a significant increase in the number of lateral roots emerged from the main axis. In this case, the humic acids were the humified fraction of greater bioactivity, since it presented greater capacity of induction of lateral roots in the initial stage of development. This action may be associated with the performance of humic materials in the seedlings as a plant regulator, promoting an increase in $\mathrm{H}^{+}$synthesis and favoring, through the formation of an electrochemical gradient, the loosening of the cell wall and, consequently, expansion of cells, tissues and organs. Therefore, the benefits of potassium humate for transplant growth may be related to its positive effects on increased fertilizeruse efficiency and/or reduced soil compaction (Osman and Rady, 2014). In addition, potassium humate has been claimed to promote plant growth by increasing RWC, MSI (Table 5), chlorophyll $a+b$, Carotenoid (Table 6). Thus, all leading to increase in the absorption of nutrients $\mathrm{N}$, $\mathrm{P}, \mathrm{K}$ and $\mathrm{Ca}$ when an application medium supplemented with $0.5 \mathrm{~g}^{-1}$ potassium humate comparing to control in Table 7.

Application of $\mathrm{P}$ fertilizer is necessary to ensure optimum vegetative growth plant and quality (Zapata and Zaharah, 2002), as well as for the acquisition, storage, and use of energy (Epstein and Bloom, 2004).
Therefore, the present study demonstrated the positive relationship between $\mathrm{P}$ foliar application and plant vegetative growth, which is supported by previous findings that $\mathrm{P}$ application increases all morphological characters (Tables 2-4). It is known that leaf development depends on a high degree of $\mathrm{P}$ concentration in the tissue because $\mathrm{P}$ plays an important role in the synthesis of starch and sucrose in photosynthesis, which increases plant dry weight (Cakmak et al., 1994). Sufficient $P$ makes efforts to increase dry matter accumulation by increasing the photosynthesis product of root and shoot (Rady et al., 2018a). Based on the above, may be the foliar application of calcium phosphate had compensated of the decrease in phosphorous absorption through the roots (Table 7); which occurs due to low in temperature of less than $13^{\circ} \mathrm{C}$, which led to the increased growth of pepper seedlings. In addition, $\mathrm{Ca}$ participate in the metabolic process of another nutrient uptake, promotes proper plant cell elongation, strengthen cell wall, and participate in an enzymatic and hormonal process (Upadhyaya, 2017). Consequently, this was reflected positively on all the studied morphological characters (Tables 2-4). In addition to the above, spraying pepper seedlings with calcium phosphate increased RWC, MSI (Table 5), chlorophyll $\mathrm{a}+\mathrm{b}$ and carotenoid (Table 6). Consequently, all this leads to an increase in the absorption of nutrients $\mathrm{N}, \mathrm{P}, \mathrm{K}$, and $\mathrm{Ca}$, which is reflected in an increase in the morphological characters of the seedlings when spraying with $800 \mathrm{mg} \mathrm{l}^{-1}$ calcium phosphate compared to the control in Table 7. Many other reports support our obtained results such as Rady et al. (2018a) and Sajid et al. (2020). 


\section{Table 4. Effect of potassium humate-supplemented medium and calcium phosphate on number of leaves transplant ${ }^{-1}$, leaf area transplant ${ }^{-1}$ and leaf area leaf ${ }^{-1}$ of pepper seedlings.

\begin{tabular}{|c|c|c|c|c|c|c|c|}
\hline \multicolumn{2}{|c|}{ Treatment } & \multirow{2}{*}{\multicolumn{2}{|c|}{$\begin{array}{c}\text { Number of } \\
\text { leaves } \\
\text { transplant }\end{array}$}} & \multirow{2}{*}{\multicolumn{2}{|c|}{$\begin{array}{c}\text { Leaf area } \\
\text { transplant } \\
\left(\mathrm{cm}^{2}\right)\end{array}$}} & \multirow{2}{*}{\multicolumn{2}{|c|}{$\begin{array}{c}\text { Leaf area leaf }-1 \\
\left(\mathrm{~cm}^{2}\right)\end{array}$}} \\
\hline \multirow{2}{*}{$\begin{array}{c}\begin{array}{c}\text { Potassium } \\
\text { humate } \\
\left(\mathrm{g} \mathrm{I}^{-1}\right)\end{array} \\
\end{array}$} & \multirow{2}{*}{$\begin{array}{c}\text { Calcium } \\
\text { phosphate } \\
\left(\mathbf{m g} \mathbf{l}^{-1}\right)\end{array}$} & & & & & & \\
\hline & & 2018 & 2019 & 2018 & 2019 & 2018 & 2019 \\
\hline $\begin{array}{c}0 \\
0.5\end{array}$ & & $\begin{array}{l}8.8^{\mathrm{A}^{*}} \\
9.0^{\mathrm{A}}\end{array}$ & $\begin{array}{l}7.3^{\mathrm{A}} \\
7.6^{\mathrm{A}} \\
\end{array}$ & $\begin{array}{l}16.0^{\mathrm{B}} \\
18.2^{\mathrm{A}}\end{array}$ & $\begin{array}{l}16.0^{\mathrm{B}} \\
18.4^{\mathrm{A}} \\
\end{array}$ & $\begin{array}{l}1.83^{\mathrm{B}} \\
2.01^{\mathrm{A}}\end{array}$ & $\begin{array}{l}2.19^{\mathrm{B}} \\
2.42^{\mathrm{A}}\end{array}$ \\
\hline & $\begin{array}{c}0 \\
100 \\
200 \\
400 \\
600 \\
\mathbf{8 0 0} \\
\mathbf{1 0 0 0} \\
\end{array}$ & $\begin{array}{l}8.8^{\text {A }} \\
8.9^{\text {A }} \\
8.9^{\text {A }} \\
8.9^{\text {A }} \\
8.9^{\text {A }} \\
9.0^{\text {A }} \\
9.0^{\text {A }}\end{array}$ & $\begin{array}{l}7.4 \mathrm{~A} \\
7.4 \mathrm{~A} \\
7.4 \mathrm{~A} \\
7.4 \mathrm{~A} \\
7.5 \mathrm{~A} \\
7.6 \mathrm{~A} \\
7.6 \mathrm{~A}\end{array}$ & $\begin{array}{l}14.3^{\mathrm{F}} \\
15.8^{\mathrm{E}} \\
16.8^{\mathrm{D}} \\
17.8^{\mathrm{BC}} \\
18.4^{\mathrm{B}} \\
19.5^{\mathrm{A}} \\
17.1^{\mathrm{CD}} \\
\end{array}$ & $\begin{array}{l}14.7^{\mathrm{D}} \\
16.2^{\mathrm{C}} \\
17.5^{\mathrm{B}} \\
17.9 \mathrm{AB} \\
18.7^{\mathrm{A}} \\
18.8^{\mathrm{A}} \\
16.8^{\mathrm{AB}}\end{array}$ & $\begin{array}{l}1.63^{\mathrm{E}} \\
1.78 \mathrm{D} \\
1.89 \mathrm{C} \\
2.01 \mathrm{~B} \\
2.07^{\mathrm{B}} \\
2.17^{\mathrm{A}} \\
1.90^{\mathrm{C}}\end{array}$ & $\begin{array}{l}1.99^{\mathrm{D}} \\
2.19^{\mathrm{C}} \\
2.36 \mathrm{~B} \\
2.42^{\mathrm{AB}} \\
2.48 \mathrm{~A} \\
2.46^{\mathrm{AB}} \\
2.23^{\mathrm{C}}\end{array}$ \\
\hline $\mathbf{0}$ & $\begin{array}{c}0 \\
100 \\
200 \\
400 \\
600 \\
800 \\
1000 \\
\end{array}$ & $\begin{array}{l}8.6^{\mathrm{a}} \\
8.7^{\mathrm{a}} \\
8.7^{\mathrm{a}} \\
8.7^{\mathrm{a}} \\
8.8^{\mathrm{a}} \\
8.9^{\mathrm{a}} \\
8.9^{\mathrm{a}}\end{array}$ & $\begin{array}{l}7.3^{\mathrm{a}} \\
7.3^{\mathrm{a}} \\
7.3^{\mathrm{a}} \\
7.3^{\mathrm{a}} \\
7.4^{\mathrm{a}} \\
7.5^{\mathrm{a}} \\
7.4^{\mathrm{a}}\end{array}$ & $\begin{array}{l}13.6^{\mathrm{i}} \\
15.0^{\mathrm{h}} \\
15.6^{\mathrm{gh}} \\
16.9^{\mathrm{ef}} \\
17.1^{\mathrm{def}} \\
17.8^{\mathrm{cde}} \\
16.4^{\mathrm{fg}}\end{array}$ & $\begin{array}{l}13.8^{\mathrm{h}} \\
15.3^{\mathrm{gh}} \\
16.4^{\mathrm{defg}} \\
16.5^{\mathrm{defg}} \\
17.1^{\mathrm{cdef}} \\
17.2^{\mathrm{cde}} \\
16.0^{\mathrm{efg}}\end{array}$ & $\begin{array}{l}1.58^{\mathrm{h}} \\
1.72^{\mathrm{fg}} \\
1.79^{\mathrm{fg}} \\
1.93^{\mathrm{de}} \\
1.95^{\mathrm{cde}} \\
2.01^{\mathrm{cd}} \\
1.84^{\mathrm{ef}}\end{array}$ & $\begin{array}{l}1.89 \mathrm{~g} \\
2.10^{\mathrm{f}} \\
2.26 \mathrm{de} \\
2.27 \mathrm{de} \\
2.32 \mathrm{~cd} \\
2.29 \mathrm{de} \\
2.17 \mathrm{ef}\end{array}$ \\
\hline 0.5 & \begin{tabular}{|c|}
0 \\
100 \\
200 \\
400 \\
6000 \\
800 \\
1000 \\
\end{tabular} & $\begin{array}{l}8.9^{\mathrm{a}} \\
9.0^{\mathrm{a}} \\
9.0^{\mathrm{a}} \\
9.0^{\mathrm{a}} \\
9.0^{\mathrm{a}} \\
9.1^{\mathrm{a}} \\
9.1^{\mathrm{a}}\end{array}$ & $\begin{array}{l}7.5^{\mathrm{a}} \\
7.5^{\mathrm{a}} \\
7.6^{\mathrm{a}} \\
7.5^{\mathrm{a}} \\
7.7^{\mathrm{a}} \\
7.8^{\mathrm{a}} \\
7.7^{\mathrm{a}}\end{array}$ & $\begin{array}{l}15.0^{\mathrm{h}} \\
16.6^{\mathrm{f}} \\
18.0^{\mathrm{cd}} \\
18.7^{\mathrm{bc}} \\
19.7^{\mathrm{b}} \\
21.2^{\mathrm{a}} \\
17.9^{\mathrm{cd}}\end{array}$ & $\begin{array}{l}15.6^{\mathrm{fg}} \\
17.2^{\mathrm{cde}} \\
18.6^{\mathrm{bc}} \\
19.3^{\mathrm{ab}} \\
20.3^{\mathrm{a}} \\
20.4^{\mathrm{a}} \\
17.7^{\mathrm{cd}}\end{array}$ & $\begin{array}{l}1.68^{\mathrm{gh}} \\
1.84^{\mathrm{ef}} \\
1.99^{\mathrm{cd}} \\
2.08^{\mathrm{bc}} \\
2.18^{\mathrm{b}} \\
2.33^{\mathrm{a}} \\
1.97^{\mathrm{cde}}\end{array}$ & $\begin{array}{l}2.08^{\mathrm{f}} \\
2.28^{\mathrm{de}} \\
2.46^{\mathrm{bc}} \\
2.57^{\mathrm{ab}} \\
2.65^{\mathrm{a}} \\
2.62^{\mathrm{a}} \\
2.29^{\mathrm{de}}\end{array}$ \\
\hline
\end{tabular}

Membrane permeability

Application of potassium humatesupplemented medium, significantly, attained higher values of RWC \% and MSI $\%$ than the untreated plants, and the trend was parallel in both experimental seasons. Application of calcium phosphate at either 600 or $800 \mathrm{mgl}^{-1}$, significantly, attained higher values of RWC \% and MSI \% than the other concentrations calcium phosphate.
Meanwhile, difference between application of calcium phosphate at 600 or $800 \mathrm{mg} \mathrm{l}^{-1}$ was not true, in the two years. The treatment combination of medium supplemented with $0.5 \mathrm{~g} \mathrm{l}^{-1}$ potassium humate together with calcium phosphate at either 600 and $800 \mathrm{mg}$ $1^{-1}$ recorded the higher values of the membrane permeability, in the two growing seasons. 


\begin{tabular}{|c|c|c|c|c|c|}
\hline \multicolumn{2}{|c|}{ Treatment } & \multirow{2}{*}{\multicolumn{2}{|c|}{ WRC (\%) }} & \multirow{2}{*}{\multicolumn{2}{|c|}{ MSI (\%) }} \\
\hline Potassium & Calcium & & & & \\
\hline$\left(\mathrm{g} \mathrm{l}^{-1}\right)$ & $\left(\mathbf{m g ~ ~ ^ { - 1 } )}\right.$ & 2018 & 2019 & 2018 & 2019 \\
\hline $\begin{array}{c}\mathbf{0} \\
\mathbf{0 . 5} \\
\end{array}$ & & $\begin{array}{l}80.7^{\mathrm{B}^{*}} \\
87.0^{\mathrm{A}}\end{array}$ & $\begin{array}{l}80.3^{\mathrm{B}} \\
86.8^{\mathrm{A}}\end{array}$ & $\begin{array}{l}70.7^{\mathrm{B}} \\
77.9^{\mathrm{A}} \\
\end{array}$ & $\begin{array}{l}67.6^{\mathrm{B}} \\
75.2^{\mathrm{A}} \\
\end{array}$ \\
\hline & $\begin{array}{c}0 \\
100 \\
200 \\
400 \\
600 \\
800 \\
1000\end{array}$ & $\begin{array}{l}81.3^{\mathrm{C}} \\
82.8^{\mathrm{BC}} \\
84.2^{\mathrm{AB}} \\
85.2^{\mathrm{A}} \\
85.7^{\mathrm{A}} \\
85.6^{\mathrm{A}} \\
82.1^{\mathrm{C}}\end{array}$ & $\begin{array}{l}81.4^{\mathrm{C}} \\
83.0^{\mathrm{BC}} \\
83.7^{\text {АВ }} \\
84.2^{\text {АВ }} \\
84.4^{\text {АВ }} \\
85.2^{\text {А }} \\
82.9^{\mathrm{BC}}\end{array}$ & $\begin{array}{l}67.0 \mathrm{C} \\
70.2 \mathrm{BC} \\
74.7 \mathrm{AB} \\
76.8 \mathrm{~A} \\
78.3 \mathrm{~A} \\
79.0 \mathrm{~A} \\
74.4 \mathrm{AB}\end{array}$ & $\begin{array}{l}61.8^{\mathrm{E}} \\
65.2^{\mathrm{D}} \\
68.9^{\mathrm{C}} \\
73.9^{\mathrm{B}} \\
78.3^{\mathrm{A}} \\
78.7^{\mathrm{A}} \\
73.1^{\mathrm{B}}\end{array}$ \\
\hline $\mathbf{0}$ & $\begin{array}{c}\text { o } \\
100 \\
200 \\
400 \\
6000 \\
800 \\
1000 \\
\end{array}$ & $\begin{array}{l}78.8^{\mathrm{h}} \\
79.8^{\mathrm{gh}} \\
81.1 \mathrm{fgh} \\
81.7^{\mathrm{fgh}} \\
82 . \mathrm{O}^{\mathrm{efg}} \\
82 . \mathrm{O}^{\mathrm{efg}} \\
79.5^{\mathrm{gh}}\end{array}$ & $\begin{array}{l}79.7 \mathrm{e} \\
80.2 \mathrm{de} \\
80.5 \mathrm{de} \\
80.4 \mathrm{de} \\
80.6 \mathrm{de} \\
80.9 \mathrm{de} \\
80.1 \mathrm{de}\end{array}$ & $\begin{array}{l}63.2^{\mathrm{f}} \\
66.6^{\mathrm{ef}} \\
71.3^{\mathrm{cde}} \\
72.9 \mathrm{cde} \\
74.3^{\mathrm{bcd}} \\
74.9 \mathrm{bcd} \\
71.7^{\mathrm{cde}}\end{array}$ & $\begin{array}{l}58.4^{\mathrm{h}} \\
61.2^{\mathrm{gh}} \\
65.0^{\mathrm{fg}} \\
69.9^{\mathrm{de}} \\
74.0^{\mathrm{bcde}} \\
74.5^{\mathrm{bcd}} \\
70.4^{\mathrm{cde}}\end{array}$ \\
\hline 0.5 & $\begin{array}{c}0 \\
100 \\
200 \\
400 \\
600 \\
800 \\
1000\end{array}$ & $\begin{array}{l}83.9^{\text {def }} \\
85.8^{\mathrm{bcd}} \\
87.3^{\mathrm{abc}} \\
88.6^{\mathrm{ab}} \\
89.3^{\mathrm{a}} \\
89.2^{\mathrm{a}} \\
84.7^{\mathrm{cde}}\end{array}$ & $\begin{array}{l}83.0^{\mathrm{cd}} \\
85.9^{\mathrm{bc}} \\
87.0^{\mathrm{ab}} \\
88.1^{\mathrm{ab}} \\
88.2^{\mathrm{ab}} \\
89.5^{\mathrm{a}} \\
85.7^{\mathrm{bc}}\end{array}$ & $\begin{array}{l}70.7^{\mathrm{df}} \\
73.8^{\mathrm{bcde}} \\
78.0^{\mathrm{abc}} \\
80.6^{\mathrm{ab}} \\
82.3^{\mathrm{a}} \\
83.1^{\mathrm{a}} \\
77.1^{\mathrm{abcd}}\end{array}$ & $\begin{array}{l}65.1^{\text {ef }} \\
69.3^{\text {ef }} \\
72.9^{\mathrm{cde}} \\
78.0^{\mathrm{b}} \\
82.7^{\mathrm{a}} \\
82.9^{\mathrm{a}} \\
75.8^{\mathrm{bc}}\end{array}$ \\
\hline
\end{tabular}

Higher RWC and MSI values were observed in bean plants applied with potassium humate than control (Table 4) this indicates that the potassium humate reflected positive effect of water uptake or reduced water loss. This may be attributed to the application of humic substances, the major component of soil organic matter; it can enhance nutrient availability and improve biological, chemical, and physical soil properties (Nardi et al., 2002; Arancon et al., 2006). As well as may be attributed to the low molecular weight fraction of humic substances which can reach the plasma membrane where it exerts its positive effects (Nardi et al., 2002), improving the RWC and MSI, and promoting nutrient uptake (Table 7) by enhancing the permeability of root cell membranes (Valdrighi et al., 1996). Similar findings were documented by Osman and Rady (2014); Taha and
Osman (2018) and Rady et al. (2018b). Increased of RWC and MSI indicates that foliar application of calcium phosphate (Table 5) probably reflected positive influence of water uptake or reduced water loss which consequently causes increase in leaf water potential. Hence, it could be concluded that the beneficial effect of a calcium phosphate on growth parameters of bean plants (Tables 2-4) has been related to the efficiency of their water uptake with nutrient elements (Table 7). This is due to the effect of phosphorus involved in several key plant functions, including regulation of some enzymes, transformation of sugars and starches, nutrient transport within the plant and transport of carbohydrates (Taiz et al., 2015). In addition, the adequate level of $\mathrm{Ca}_{2}{ }^{+}$ is required in the external medium to maintain the selectivity and integrity of cell membrane (Upadhyaya, 2017). 


\section{Leaf photosynthetic pigments}

Application of growth medium with 0.5 $\mathrm{g}^{-1}$ potassium humate gave the highest significant values in leaf chlorophyll $a, b$, $\mathrm{a}+\mathrm{b}$ and carotenoids contents comparing to control, in both experimental seasons. Generally, calcium phosphate application with $1000 \mathrm{mg} \mathrm{l}^{-1}$ gave the highest significant values in leaf chlorophyll $a, b, a+b$ and carotenoids contents comparing to other concentrations, whereas, no significant increases were detected between the levels 800 and $1000 \mathrm{mg} \mathrm{l}^{-1}$ on leaf chlorophyll a, b, $\mathrm{a}+\mathrm{b}$ and carotenoids content, and the trend was parallel in both experimental seasons. Generally, the best combined treatment was potassium humate-supplemented medium at $0.5 \mathrm{~g} \mathrm{l}^{-1}$ and calcium phosphate at 800 or $1000 \mathrm{mg} \mathrm{l}^{-1}$, in both season.

Table 6. Effect of potassium humate-supplemented medium and calcium phosphate on leaf photosynthetic pigments of pepper seedlings.

\begin{tabular}{|c|c|c|c|c|c|c|c|c|c|}
\hline \multicolumn{2}{|c|}{ Treatment } & & \multirow{2}{*}{\multicolumn{2}{|c|}{$\begin{array}{c}\text { Carotenoid } \\
\left(\mathrm{mg} / \mathbf{m m}^{2} \text { FW }\right)\end{array}$}} \\
\hline Potassium & Calcium & \multicolumn{2}{|c|}{$\stackrel{\left.\underset{\left(m g / \mathbf{m m}^{2}\right.}{\mathbf{F}} \mathbf{F W}\right)}{ }$} & \multicolumn{2}{|c|}{$\underset{\left(\mathbf{m g} / \mathbf{m m}^{\mathbf{2}} \mathbf{F W}\right)}{\mathbf{b}}$} & \multicolumn{2}{|c|}{$\begin{array}{c}\mathbf{a}+\mathbf{b} \\
\left(\mathbf{m g} / \mathbf{m m}^{2} \mathbf{F W}\right)\end{array}$} & & \\
\hline $\begin{array}{c}\text { humate } \\
\left(\mathrm{g} \mathrm{l}^{-1}\right)\end{array}$ & $\begin{array}{c}\text { phosphate } \\
\left(\mathrm{mg} \mathrm{l}^{-1}\right)\end{array}$ & 2018 & 2019 & 2018 & 2019 & 2018 & 2019 & 2018 & 2019 \\
\hline $\begin{array}{c}0 \\
0.5\end{array}$ & & $\begin{array}{l}0.131^{\mathrm{B} *} \\
0.152^{\mathrm{A}}\end{array}$ & $\begin{array}{l}0.128^{\mathrm{B}} \\
0.141^{\mathrm{A}}\end{array}$ & $\begin{array}{l}0.071^{\text {в }} \\
0.077^{\text {А }}\end{array}$ & $\begin{array}{l}0.067 \text { в } \\
0.072 \text { А }\end{array}$ & $\begin{array}{l}0.201^{\mathrm{B}} \\
0.229^{\mathrm{A}}\end{array}$ & $\begin{array}{l}0.195^{\text {B }} \\
0.212^{\text {A }}\end{array}$ & $\begin{array}{l}0.045^{\text {B }} \\
0.051^{\text {A }}\end{array}$ & $\begin{array}{l}0.038^{\text {B }} \\
0.043^{\text {A }}\end{array}$ \\
\hline & $\begin{array}{c}0 \\
100 \\
200 \\
400 \\
600 \\
800 \\
1000 \\
\end{array}$ & $\begin{array}{l}0.082^{\mathrm{F}} \\
0.122^{\mathrm{E}} \\
0.139^{\mathrm{D}} \\
0.153^{\mathrm{C}} \\
0.157^{\mathrm{BC}} \\
0.164^{\mathrm{AB}} \\
0.171^{\mathrm{A}} \\
\end{array}$ & $\begin{array}{l}0.071^{\mathrm{F}} \\
0.112^{\mathrm{E}} \\
0.124^{\mathrm{D}} \\
0.146^{\mathrm{C}} \\
0.158^{\mathrm{B}} \\
0.162^{\mathrm{AB}} \\
0.168^{\mathrm{A}} \\
\end{array}$ & $\begin{array}{l}0.044^{\mathrm{E}} \\
0.064^{\mathrm{D}} \\
0.073^{\mathrm{C}} \\
0.081^{\mathrm{B}} \\
0.083^{\mathrm{AB}} \\
0.086^{\mathrm{AB}} \\
0.088^{\mathrm{A}} \\
\end{array}$ & $\begin{array}{l}0.037^{\mathrm{F}} \\
0.056^{\mathrm{E}} \\
0.063^{\mathrm{D}} \\
0.074^{\mathrm{C}} \\
0.081^{\mathrm{B}} \\
0.085^{\mathrm{A}} \\
0.088^{\mathrm{A}}\end{array}$ & $\begin{array}{l}0.126^{\mathrm{F}} \\
0.186^{\mathrm{E}} \\
0.212^{\mathrm{D}} \\
0.234^{\mathrm{C}} \\
0.239^{\mathrm{BC}} \\
0.250^{\mathrm{AB}} \\
0.259^{\mathrm{A}} \\
\end{array}$ & $\begin{array}{l}0.108^{\mathrm{F}} \\
0.169^{\mathrm{E}} \\
0.186^{\mathrm{D}} \\
0.221^{\mathrm{C}} \\
0.239^{\mathrm{B}} \\
0.247^{\mathrm{B}} \\
0.255^{\mathrm{A}} \\
\end{array}$ & $\begin{array}{l}0.035^{\mathrm{C}} \\
0.044^{\mathrm{B}} \\
0.049^{\mathrm{AB}} \\
0.051^{\mathrm{A}} \\
0.052^{\mathrm{A}} \\
0.054^{\mathrm{A}} \\
0.054^{\mathrm{A}}\end{array}$ & $\begin{array}{l}0.030^{\mathrm{D}} \\
0.035^{\mathrm{C}} \\
0.041^{\mathrm{B}} \\
0.043^{\mathrm{AB}} \\
0.045^{\mathrm{A}} \\
0.046^{\mathrm{A}} \\
0.044^{\mathrm{AB}} \\
\end{array}$ \\
\hline $\mathbf{0}$ & $\begin{array}{c}0 \\
100 \\
200 \\
400 \\
600 \\
800 \\
1000\end{array}$ & $\begin{array}{l}0.078^{\mathrm{h}} \\
0.114^{\mathrm{g}} \\
0.129^{\mathrm{f}} \\
0.138^{\mathrm{def}} \\
0.144^{\mathrm{df}} \\
0.151^{\mathrm{cd}} \\
0.161^{\mathrm{bc}}\end{array}$ & $\begin{array}{l}0.065^{\mathrm{j}} \\
0.106^{\mathrm{h}} \\
0.118^{\mathrm{g}} \\
0.141^{\mathrm{e}} \\
0.152^{\mathrm{d}} \\
0.155^{\mathrm{cd}} \\
0.160^{\mathrm{cd}}\end{array}$ & $\begin{array}{l}0.044^{\mathrm{i}} \\
0.062^{\mathrm{h}} \\
0.070^{\mathrm{fg}} \\
0.076^{\text {ef }} \\
0.078^{\mathrm{de}} \\
0.081^{\mathrm{cde}} \\
0.084^{\mathrm{bcd}}\end{array}$ & $\begin{array}{l}0.035^{k} \\
0.052^{i} \\
0.060^{h} \\
0.072^{f} \\
0.080^{d e} \\
0.082^{c d} \\
0.085^{b c}\end{array}$ & $\begin{array}{l}0.122^{\mathrm{g}} \\
0.176^{\mathrm{f}} \\
0.199^{\mathrm{e}} \\
0.214^{\mathrm{de}} \\
0.222^{\mathrm{d}} \\
0.231^{\mathrm{cd}} \\
0.245^{\mathrm{bc}}\end{array}$ & $\begin{array}{l}0.100^{\mathrm{j}} \\
0.159^{\mathrm{h}} \\
0.178^{\mathrm{g}} \\
0.214^{\mathrm{e}} \\
0.232^{\mathrm{d}} \\
0.237^{\mathrm{cd}} \\
0.245^{\mathrm{c}}\end{array}$ & $\begin{array}{l}0.033^{\mathrm{e}} \\
0.040^{\mathrm{de}} \\
0.046^{\mathrm{cd}} \\
0.048^{\mathrm{cd}} \\
0.049^{\mathrm{bc}} \\
0.051^{\mathrm{abc}} \\
0.052^{\mathrm{abc}}\end{array}$ & $\begin{array}{l}0.028^{\mathrm{g}} \\
0.032^{\mathrm{g}} \\
0.039^{\mathrm{ef}} \\
0.040^{\mathrm{def}} \\
0.042^{\mathrm{def}} \\
0.042^{\mathrm{def}} \\
0.041^{\mathrm{cde}}\end{array}$ \\
\hline 0.5 & $\begin{array}{c}0 \\
100 \\
200 \\
400 \\
600 \\
800 \\
1000\end{array}$ & $\begin{array}{l}0.086^{\mathrm{h}} \\
0.131^{\text {ef }} \\
0.149^{\mathrm{cd}} \\
0.168^{\mathrm{a}} \\
0.170^{\mathrm{a}} \\
0.178^{\mathrm{a}} \\
0.182^{\mathrm{a}}\end{array}$ & $\begin{array}{l}0.077^{\mathrm{i}} \\
0.118^{\mathrm{g}} \\
0.129^{\mathrm{f}} \\
0.152^{\mathrm{d}} \\
0.163^{\mathrm{bc}} \\
0.170^{\mathrm{ab}} \\
0.176^{\mathrm{a}}\end{array}$ & $\begin{array}{l}0.044^{\mathrm{i}} \\
0.066^{\mathrm{gh}} \\
0.076^{\text {ef }} \\
0.086^{\mathrm{abcd}} \\
0.087^{\mathrm{abc}} \\
0.091^{\mathrm{ab}} \\
0.092^{\mathrm{a}}\end{array}$ & $\begin{array}{l}0.040^{\mathrm{j}} \\
0.061^{\mathrm{h}} \\
0.066^{\mathrm{g}} \\
0.076^{\mathrm{ef}} \\
0.083^{\mathrm{cd}} \\
0.087^{\mathrm{ab}} \\
0.090^{\mathrm{a}}\end{array}$ & $\begin{array}{l}0.130^{\mathrm{g}} \\
0.197^{\mathrm{e}} \\
0.225^{\mathrm{cd}} \\
0.254^{\mathrm{ab}} \\
0.257^{\mathrm{ab}} \\
0.269^{\mathrm{a}} \\
0.274^{\mathrm{a}}\end{array}$ & $\begin{array}{l}0.116^{\mathrm{i}} \\
0.179^{\mathrm{g}} \\
0.195^{\mathrm{f}} \\
0.228^{\mathrm{d}} \\
0.246^{\mathrm{bc}} \\
0.257^{\mathrm{ab}} \\
0.266^{\mathrm{a}}\end{array}$ & $\begin{array}{l}0.036^{\mathrm{e}} \\
0.047^{\mathrm{cd}} \\
0.052^{\mathrm{abc}} \\
0.054^{\mathrm{abc}} \\
0.056^{\mathrm{ab}} \\
0.057^{\mathrm{ab}} \\
0.057^{\mathrm{a}}\end{array}$ & $\begin{array}{l}0.031^{\mathrm{g}} \\
0.037^{\mathrm{f}} \\
0.044^{\mathrm{bcd}} \\
0.046^{\mathrm{abc}} \\
0.048^{\mathrm{abc}} \\
0.049^{\mathrm{ab}} \\
0.047^{\mathrm{a}}\end{array}$ \\
\hline
\end{tabular}

Many authors working on humic substances on Solanaceae family coincides our results such as Osman and Ewees (2008) found that the chlorophyll $a+b$ contents were significantly higher in leaf tomato plants irrigated with either fresh water or saline water. In pot experiments, Rady et al. (2018b) indicated that the application of potassium humate at $0.2 \mathrm{~g} \mathrm{~kg}^{-}$ 1 soil increased chlorophyll $a+b$, total carotenoids and chlorophyll fluorescence measured in terms of $\mathrm{Fv} / \mathrm{Fm}$ and performance index (PI) of eggplant plants compared to the untreated control. Leaf photosynthetic pigments content (chlorophyll $\mathrm{a}+\mathrm{b}$ and carotenoid synthesis) are dependent upon mineral nutrition (Daughtry et al., 2000). Leaf photosynthetic pigments depend on phosphorus content, since it facilitates the plant for stability in unfavorable conditions (Bojovic and Stojanovic, 2006). However, the facilitation of biochemical characteristics and biosynthesis of leaf pigment molecules depends on the uptake of optimal phosphorus levels (Waraich et al., 2015). Optimal phosphorus conditions, in apricot seedlings, have been shown to increase chlorophyll $\mathrm{a}+\mathrm{b}$ content and plant growth (Dutt et al., 2013). Previous studies have also found that phosphorus application increases the biomass and total carotenoid 
production of a blue-green alga Spirulina platensis (Celekli et al., 2009), whereas phosphorus deficiency decreases protein and total chlorophyll contents (Liang et al., 2005). Kazemi (2014) found that leaf chlorophyll content in tomato plants increased from 13.12 in the control to 22.41 and 21.14 (SPAD) with $30 \mathrm{ppm}$ humic acid and $15 \mathrm{mM} \mathrm{Ca}$ foliar application. In addition, he said that the interaction between $\mathrm{HA}$ and $\mathrm{Ca}$ (30 ppm humic acid $+15 \mathrm{mM} \mathrm{Ca}$ ) gave the highest value (25.14) in the respect, comparing with the control plants.

\section{Leaf $N, P, K$ and Ca contents}

Application of growth medium with 0.5 $\mathrm{g}^{-1}$ potassium humate gave the highest significant values on leaf $\mathrm{N}, \mathrm{P}, \mathrm{K}$ and $\mathrm{Ca}(\mathrm{mg}$ $\left.\mathrm{g}^{-1} \mathrm{DW}\right)$ than the growth medium without potassium humate treatment, in both seasons. Regardless of the control treatment, spraying calcium phosphate at a concentration of $100 \mathrm{mg}^{-1}$ significantly recorded higher mean values of leaf $\mathrm{N}$ content, with an increased in calcium phosphate concentration up to $1000 \mathrm{mg} \mathrm{l}^{-1}$ led to a gradual decrease in leaf $\mathrm{N}$ content. Therefore, the lowest leaf $\mathrm{N}$ content was at a concentration of $1000 \mathrm{mg}^{-1}$ of calcium phosphate. On the other hand, application of calcium phosphate at $1000 \mathrm{mg} \mathrm{l}^{-1}$, significantly, attained higher values of leaf $\mathrm{P}$ and $\mathrm{Ca}$ content. While, application of calcium phosphate 200 or $400 \mathrm{mg} \mathrm{l}^{-1}$ gave the highest significant values on leaf $\mathrm{K}$ content, in the two growing seasons of 2018 and 2019. The treatment combination of medium supplemented with $0.5 \mathrm{~g} \mathrm{l}^{-1}$ potassium humate together with foliar application of calcium phosphate $100 \mathrm{mg} \mathrm{l}^{-1}$ recorded the higher values of leaf $\mathrm{N}$ content, or with $1000 \mathrm{mg} \mathrm{l}^{-1}$ recorded the best values of leaf $\mathrm{P}$ and $\mathrm{Ca}$ content, or with concentrations at either 200 and $400 \mathrm{mg} \mathrm{l}^{-1}$ recorded the higher values of leaf $\mathrm{K}$ content, in both seasons.

The positive effect of potassium humate on $\mathrm{N}, \mathrm{P}, \mathrm{K}$ and $\mathrm{Ca}$ leaf content might be due to their positive effect on stability of membrane permeability; MSI and RWC (Table 5). This led to enhancing roots dry weight (Tables 2 - 4), which reflected positively on uptake of nutrients $\mathrm{N}, \mathrm{P}, \mathrm{K}$ and $\mathrm{Ca}$ when an application growth medium supplemented with $0.5 \mathrm{~g} \mathrm{l}^{-1}$ potassium humate comparing to control. This may indicate that potassium humate improved the chemical properties of soil by increasing the number of micro-organisms which can enhance nutrient cycling and increasing the bio-availability of mineral nutrients to the transplant roots (Sayed et al., 2007). 
Table 7. Effect of potassium humate-supplemented medium and calcium phosphate on leaf elemental of pepper seedlings.

\begin{tabular}{|c|c|c|c|c|c|c|c|c|c|}
\hline \multicolumn{2}{|c|}{ Treatment } & \multirow{2}{*}{\multicolumn{2}{|c|}{$\begin{array}{c}\mathbf{N} \\
\left(\mathrm{mg} \mathrm{g}^{-1} \mathrm{DW}\right)\end{array}$}} & \multirow{2}{*}{\multicolumn{2}{|c|}{$\begin{array}{c}P \\
\left(\mathrm{mg} \mathrm{g}^{-1} \mathrm{DW}\right)\end{array}$}} & \multirow{2}{*}{\multicolumn{2}{|c|}{$\begin{array}{c}\mathrm{K} \\
\left(\mathrm{mg} \mathrm{g}^{-1} \mathrm{DW}\right)\end{array}$}} & \multirow{2}{*}{\multicolumn{2}{|c|}{$\begin{array}{c}\mathrm{Ca} \\
\left(\mathrm{mg} \mathrm{g}^{-1} \mathbf{D W}\right)\end{array}$}} \\
\hline \multirow{2}{*}{$\begin{array}{c}\text { Potassium } \\
\text { humate } \\
\left(\mathrm{g} \mathrm{l}^{-1}\right)\end{array}$} & \multirow{2}{*}{$\begin{array}{c}\text { Calcium } \\
\text { phosphate } \\
\left(\mathrm{mg} \mathrm{l}^{-1}\right)\end{array}$} & & & & & & & & \\
\hline & & 2018 & 2019 & 2018 & 2019 & 2018 & 2019 & 2018 & 2019 \\
\hline \multirow{9}{*}{$\begin{array}{c}0 \\
0.5 \\
\end{array}$} & & $22.0^{\mathrm{B} *}$ & $23.0^{\mathrm{B}}$ & $1.67^{\mathrm{B}}$ & $1.61^{\mathrm{B}}$ & $19.9^{\mathrm{B}}$ & $19.7^{\mathrm{B}}$ & $13.4^{\mathrm{B}}$ & $13.3^{\mathrm{B}}$ \\
\hline & & $24.5^{\mathrm{A}}$ & $25.4^{\mathrm{A}}$ & $1.86^{\mathrm{A}}$ & $1.81^{\mathrm{A}}$ & $22.0^{\mathrm{A}}$ & $21.8^{\mathrm{A}}$ & $14.8^{\mathrm{A}}$ & $14.7^{\mathrm{A}}$ \\
\hline & 0 & $23.4^{\mathrm{D}}$ & $24.1^{\mathrm{C}}$ & $1.06^{\mathrm{D}}$ & $0.99^{\mathrm{E}}$ & $20.1^{\mathrm{C}}$ & $20.4^{\mathrm{DE}}$ & $10.3^{\mathrm{G}}$ & $10.1^{\mathrm{G}}$ \\
\hline & 100 & $30.2^{\mathrm{A}}$ & $29.9^{\mathrm{A}}$ & $1.55^{\mathrm{C}}$ & $1.51^{\mathrm{D}}$ & $21.6^{\mathrm{B}}$ & $21.2^{\mathrm{CD}}$ & $11.3^{\mathrm{F}}$ & $11.0^{\mathrm{F}}$ \\
\hline & 200 & $27.7^{\text {в }}$ & $28.1^{\mathrm{AB}}$ & $1.83^{\mathrm{B}}$ & $1.71^{\mathrm{C}}$ & $22.5^{\mathrm{A}}$ & $22.7^{\mathrm{A}}$ & $12.6^{\mathrm{E}}$ & $13.1^{\mathrm{E}}$ \\
\hline & 400 & $26.2^{\mathrm{C}}$ & $27.5^{\text {B }}$ & $1.93^{\mathrm{A}}$ & $1.87^{\mathrm{B}}$ & $22.4^{\mathrm{A}}$ & $22.3^{\mathrm{AB}}$ & $14.2^{\mathrm{D}}$ & $14.1^{\mathrm{D}}$ \\
\hline & 600 & $19.6^{\mathrm{E}}$ & $22.1^{\mathrm{D}}$ & $1.97^{\mathrm{A}}$ & $1.92 \mathrm{AB}$ & $22.0^{\mathrm{AB}}$ & $21.7^{\mathrm{BC}}$ & $15.2^{\mathrm{C}}$ & $14.9^{\mathrm{C}}$ \\
\hline & 800 & $18.2^{\mathrm{F}}$ & $19.8^{\mathrm{E}}$ & $1.99^{\mathrm{A}}$ & $1.97 \mathrm{~A}$ & $20.2^{\mathrm{C}}$ & $19.8^{\mathrm{E}}$ & $17.2^{\mathrm{B}}$ & $16.8^{\mathrm{B}}$ \\
\hline & 1000 & $17.4^{\mathrm{F}}$ & $17.9^{\mathrm{F}}$ & $2.02^{\mathrm{A}}$ & $1.99^{\mathrm{A}}$ & $17.6^{\mathrm{D}}$ & $17.2^{\mathrm{F}}$ & $18.2^{\mathrm{A}}$ & $17.8^{\mathrm{A}}$ \\
\hline \multirow{7}{*}{ 0 } & 0 & $22.6^{f}$ & $22.7^{\mathrm{g}}$ & $1.01^{\mathrm{h}}$ & $0.95^{f}$ & $19.1^{\mathrm{c}}$ & $19.4^{\mathrm{fg}}$ & $9.8^{\mathrm{h}}$ & $9.6^{\mathrm{i}}$ \\
\hline & 100 & $28.5^{b c}$ & $28.3^{b c d}$ & $1.43^{\mathrm{g}}$ & $1.42^{\mathrm{e}}$ & $20.5^{b}$ & $20.1^{\text {ef }}$ & $10.7^{\mathrm{g}}$ & $10.5^{\mathrm{h}}$ \\
\hline & 200 & $26.1^{d}$ & $26.6^{\mathrm{cde}}$ & $1.74^{\mathrm{ef}}$ & $1.61^{\mathrm{d}}$ & $21.3^{b}$ & $21.5^{\mathrm{cd}}$ & $11.9^{f}$ & $12.4^{\mathrm{g}}$ \\
\hline & 400 & $24.5^{\mathrm{e}}$ & $26.1^{\mathrm{de}}$ & $1.83^{\mathrm{de}}$ & $1.72^{\mathrm{c}}$ & $21.2^{b}$ & $21.1^{\mathrm{cde}}$ & $13.5^{\mathrm{e}}$ & $13.3^{f}$ \\
\hline & 600 & $18.6^{\mathrm{h}}$ & $21.2^{\mathrm{g}}$ & $1.87^{\mathrm{de}}$ & $1.80^{\mathrm{bc}}$ & $20.8^{b}$ & $20.6^{\text {def }}$ & $14.4^{\mathrm{d}}$ & $14.1^{\mathrm{ef}}$ \\
\hline & 800 & $17.2^{\text {ih }}$ & $18.5^{\mathrm{i}}$ & $1.88^{\mathrm{d}}$ & $1.87^{\mathrm{b}}$ & $19.2^{\mathrm{c}}$ & $18.8^{\mathrm{gh}}$ & $16.3^{c}$ & $16.0^{\mathrm{c}}$ \\
\hline & 1000 & $16.5^{\mathrm{j}}$ & $17.3^{i}$ & $1.90^{\mathrm{cd}}$ & $1.89^{\mathrm{b}}$ & $17.0^{\mathrm{d}}$ & $16.6^{\mathrm{i}}$ & $17.6^{\mathrm{b}}$ & $17.2^{\mathrm{b}}$ \\
\hline \multirow{7}{*}{0.5} & 0 & $24.2 \mathrm{e}$ & $25.4^{\text {ef }}$ & $1.11^{\mathrm{h}}$ & $1.04^{\mathrm{f}}$ & $21.1^{b}$ & $21.4^{\mathrm{cd}}$ & $10.8^{\mathrm{g}}$ & $10.6^{\mathrm{h}}$ \\
\hline & 100 & $31.9^{\mathrm{a}}$ & $31.4^{\mathrm{a}}$ & $1.66^{f}$ & $1.60^{d}$ & $22.7^{a}$ & $22.3^{b c}$ & $11.9^{f}$ & $11.6^{\mathrm{g}}$ \\
\hline & 200 & $29.3^{b}$ & $29.6^{\mathrm{ab}}$ & $1.93^{\mathrm{bcd}}$ & $1.80^{\mathrm{bc}}$ & $23.7^{\mathrm{a}}$ & $23.9^{\mathrm{a}}$ & $13.3^{\mathrm{e}}$ & $13.8^{f}$ \\
\hline & 400 & $27.9^{c}$ & $29.0^{a b c}$ & $2.04 \mathrm{abc}$ & $2.01^{\mathrm{a}}$ & $23.6^{a}$ & $23.5^{a}$ & $15.0^{d}$ & $14.8^{d \mathrm{~d}}$ \\
\hline & 600 & $20.5^{g}$ & $22.9^{\mathrm{fg}}$ & $2.07^{\mathrm{ab}}$ & $2.03^{\mathrm{a}}$ & $23.2^{\mathrm{a}}$ & $22.9^{a b}$ & $16.1^{\mathrm{c}}$ & $15.7^{\mathrm{cc}}$ \\
\hline & 800 & $19.2^{\mathrm{gh}}$ & $21.1^{\mathrm{gh}}$ & $2.10^{\mathrm{a}}$ & $2.08^{a}$ & $21.3^{b}$ & $20.8^{\mathrm{de}}$ & $18.1^{\mathrm{ab}}$ & $17.7^{\mathrm{al}}$ \\
\hline & 1000 & $18.2^{\mathrm{hi}}$ & $18.6^{\mathrm{hi}}$ & $2.13^{\mathrm{a}}$ & $2.09^{\mathrm{a}}$ & $18.3^{c}$ & $17.9^{\mathrm{h}}$ & $18.9^{\mathrm{a}}$ & $18.5^{\mathrm{a}}$ \\
\hline
\end{tabular}

In addition, media supplemented with humic acid (0.5 $\mathrm{g} \mathrm{l}^{-1}$ media) also promoted the absorption of nutrients by preventing their precipitation in the nutrient solution (Osman and Rady, 2014). Also, potassium humate similarly as a good fertilizer state creating more accessibility for the nutrients (Osman and Ewees, 2008 and Taha and Osman 2018) by reduction soil $\mathrm{pH}$ value, thus increasing the availability of mineral nutrients to be absorbed by plant roots. Related to our results on Solanaceae family plants, Osman and Rady (2014) reported that the media supplemented with humic acid (0.5 $\mathrm{g} \mathrm{l}^{-1}$ media) gave significant higher transfer factor (uptake) values for $\mathrm{N}, \mathrm{P}$, and $\mathrm{K}$ in 4-week-old tomato and eggplant transplants produced than corresponding humic acid-free media. In pot experiments, Rady et al. (2018b) indicated that the application of potassium humate at $0.2 \mathrm{~g} \mathrm{~kg}^{-}$
${ }^{1}$ soil as a single used or $0.2 \mathrm{~g} \mathrm{~kg}^{-1}$ soil when it was used in combination with biochar significantly increased leaf $\mathrm{NO}_{3}{ }^{-}, \mathrm{NO}_{2}{ }^{-}$and $\mathrm{K}^{+}$contents of eggplant plants compared to the untreated control. The positive effect of calcium phosphate on $\mathrm{P}$ and $\mathrm{Ca}$ leaf content (Table 7) might be due to their positive effect on stability of membrane permeability; MSI and RWC (Table 5) and increased contents of photosynthetic pigments (Table 6). Additionally, the spraying of calcium phosphate increased phosphorous and calcium content inside the leaf of pepper transplants. While the effect of calcium phosphate were less on leaf $\mathrm{N}$ and $\mathrm{K}$ content of pepper transplants for may be to the antagonism between the metabolism of elements. Kazemi (2014) reported that leaf $\mathrm{N}$ and $\mathrm{K}$ content of tomato was not affected by foliar application of calcium alone, but humic acid application resulted in a 
significant increase in the leaf $\mathrm{N}$ and $\mathrm{K}$ content. In addition, he noticed that humic acid at $30 \mathrm{ppm}+\mathrm{Ca}$ at $15 \mathrm{mM}(2.51$ and $2 \%$, respectively) was superior in this respect. Foliar application of humic acid alone significantly increased the nitrate reductase activity. Ilias et al. (2007) found that application of humic acid and $\mathrm{Ca}$ promoted the accumulation of $\mathrm{K}, \mathrm{B}, \mathrm{Mg}, \mathrm{Ca}$ and $\mathrm{Fe}$ in leaves of okra plants. Tejashvini and Thippeshappa (2017) revealed that application of different $\mathrm{Ca}$ sources, as foliar spray will enhance the nutrient content and uptake by tomato crop. As well as, all the sources of calcium found to be effective and significantly increased nutrient content and uptake.

\section{REFRENCES}

A. O. A. C. 1995. Official methods of analysis (12th ed.). Washington, DC: Association of Official Analytical Chemists.

Arancon, N.Q., C.A. Edwards, S. Lee and R. Byrne 2006 Effects of humic acids from vermicomposts on plant growth. Eur J Soil Biol 46: 65-69.

Bojovic, B. and Stojanovic, J. 2006. Some wheat leaf characteristics in dependence of fertilization, Kragujevac Journal of Science. 28: 139-146.

Buddh, S. 2014. Comparative Study Of Rock Phosphate and Calcium Phosphate On The Growth \&Biochemistry Of Brassica Juncea And It's Impact On Soil Heath. IOSR Journal of Environmental Science, Toxicology and Food Technology (IOSR-JESTFT). 8 (11) Ver. III: 22 - 39. Www.iosrjournals.org

Cakmak, I.; Hengeler, C. and Marschner, H. 1994. Partitioning of shoot and root dry matter and carbohydrates in bean plants suffering from phosphorus, potassium and magnesium deficiency, Journal of Experimental Botany. 45(9): 1245-1250.

Celekli, A.; Yavuzatmaca, M. and Bozkurt, H. 2009. Modeling of biomass
Within the experimental conditions studied, it has been concluded that this work provided evidence to the role of potassium humate and/or calcium phosphate application act to directly at improving the morphological characters, membrane permeability, leaf photosynthetic pigments and leaf elemental contents of pepper transplants produced (Capsicum annuum 'Omega' F1 Hybrid). Generally, the growth medium supplemented with $0.5 \mathrm{~g}^{-1}$ potassium humate in integration with foliar application of calcium phosphate at 600 or $800 \mathrm{mg} \mathrm{l}^{-1}$ act to enhancing the plant physiobiochemical components, which reflected in high growth of pepper seedlings.

production by Spirulina platensis as function of phosphate concentrations and $\mathrm{pH}$ regimes, Bioresource Technology. 100(14): 3625-3629.

Chapman, H. D., P. F. Pratt, 1961. Methods of analysis for soil, plants and water. Berkeley, CA, USA: University of California, Division of Agricultural Science; p. 56-63.

Colpas-Castillo, F., A. T. Dunoyer and J. M. Camargo 2018. Agricultural soils strengthening employing humic acids and its effect on plant growth chilli pepper and eggplant. Emirates Journal of Food and Agriculture. 30 (11): 941-945. doi: 10.9755/ejfa.2018.v30.i11.1845

Daughtry, C.S.T.; Walthall, C.L.; Kim, M.S.; Brown de Colstoun, E. and McMurtrey, J.E. 2000. Estimating corn leaf chlorophyll concentration from leaf and canopy reflectance, Remote Sensing of Environment. 74(2): 229-239.

Dutt, S.; Sharma, S.D. and Kumar, P. 2013. Inoculation of apricot seedlings with indigenous arbuscular mycorrhizal fungi in optimum phosphorus fertilization for quality growth attributes, Journal of Plant Nutrition. 36(1): 15-31.

Epstein, E. and Bloom, A.J. 2004. Mineral nutrition of plants: Principles and 
perspectives (Second Edition). Sunderland, MA: Sinauer Associates, Inc.

Gomez, K. A. and A. A. Gomez 1984. Statistical analysis procedures for agricultural research (pp. 25-30). New York, NY: John Wiley and Sons.

Hafez, A. R. and D. S. Mikkelsen 1981. Colorimetric determination of nitrogen for evaluating the nutritional status of rice. Communications in Soil Science and Plant Analysis, 12, 61-69. doi:10.1080/00103628109367127

Hayat, S., B. Ali, S. A. Hasan, and A. Ahmad 2007. Brassinosteroid enhanced the level of antioxidants under cadmium stress in Brassica juncea. Environ. Exp. Bot.60, 33-41. doi:10.1016/j .envexpbot.2006.06.002.

https://www.humintech.com/agriculture/pr oducts/powhumus-wsg-85

Ilias, I., Ouzounidou, G., Giannakoula, A., and Papadopoulou, P. 2007. Effects of gibberellic acid and prohexadionecalcium on growth, chlorophyll fluorescence and quality of Okra plant. Biol. Plantarum 51(3): 575-578.

InfoStat 2016. InfoStat software estadistico User's Guide. Version 26/01/2016 InfoStat Institute. https://www.infostat.com.ar/index.php

Jindo, K., S. A. Martim, E. C. Navarro, F. Pérez-Alfocea, T. Hernandez, C. Garcia, N. O. Aguiar and L. P. Canellas 2011. Root growth promotion by humic acids from composted and non-composted urban organic wastes. Plant Soil.353: 209-220.DOI 10.1007/s11104-011-1024-3

Kazemi M. 2014. Effect of Foliar Application of Humic Acid and Calcium Chloride on tomato growth. Bulletin of Environment, Pharmacology and Life Sciences, 3(3): 41-46.

Liang, X.L.; Lin, Y.C.; Nian, H. and Xie, L.X. 2005. The effect of low phosphorus stress on main physiological traits of different maize genotypes, Acta Agronomica Sinica. 31(5): 667-669.

Moran, R. and D. Porath 1980. Chlorophyll determination in intact tissues using n,n-dimethylformamide. Plant Physiol. 65, 478-9.
Nardi M.R., Diego, P., Fabiano, R., \& Muscolo, A. 1999. Biological activity of humic substances extracted from soils under different vegetation cover. Communications in Soil Sciences Plant Analysis, 30, 621-634. doi:10.1080/00103629909370232

Nardi, S., Pizzeghello, D., Muscolo, A., and Vianello, A. 2002. Physiological effects of humic substances on higher plants. Soil Biology and Biochemistry, 34, 1527- 1536. doi:10.1016/S00380717(02)00174-8

Osman A. Sh., and Rady, M.M. 2014. Effect of humic acid as an additive to growing media to enhance the production of eggplant and tomato transplants. The Journal of Horticultural Science and Biotechnology, 89 (3): 237-244. https://doi.org/10.1080/14620316.2014.11 513074

Osman, A. Sh. and M. S. Ewees 2008. The possible use of humic acid incorporated with drip irrigation system to alleviate the harmful effects of saline water on tomato plants. Fayoum J. Agric Res. \& Dev., 22 (1): $\quad 52 \quad 70$. http://www.fayoum.edu.eg/agriculture/hor ticulture/pdf/DrAshraf12.pdf

Rady, M. M. 2011. Effects on growth, yield, and fruit quality in tomato (Lycopersicon esculentum Mill.) using a mixture of potassium humate and farmyard manure as an alternative to mineral-N fertiliser. The Journal of Horticultural Science \& Biotechnology, 86(3): 249-254.

Rady, M. M., and Osman, A. Sh. 2011. Effects of the application of 'cash' on the growth, fruit yield, and nutrient status of tomato (Solanum lycopersicum L.) grown in reclaimed saline soil. The Journal of Horticultural Science \& Biotechnology, 86(6): 626-630.

Rady, M. M.; El-Shewy, A. A.; Seif ElYazal, M. A. and Kariman E.S. Abdelaal 2018. Response of salt-stressed common bean plant performances to foliar application of phosphorus (MAP). International Letters of Natural Sciences, 72: 


$\begin{array}{lll}\text { doi:10.18052/www.scipress.com/ILNS.72. } & \begin{array}{l}\text { development. } \\ \text { Incorporated. }\end{array} \\ 7 & \text { Sinauer } & \text { Associates, } \\ \text { Rady, M.M., M.M.M. Abd El-Azeem, Tejashvini, A. and Thippeshappa, G.N. }\end{array}$

T.A. Abd El-Mageed and M.T. Abdelhamid 2018. Integrative potassium humate and biochar application reduces salinity effects and contaminants, and improves growth and yield of eggplant grown under saline conditions. International Journal for Empirical Education and Research. 1 (2): 37-56.

Russo, R. O. and Berlyn, G. P. 1990. The use of organic biostim- ulants to help low input sustainable agriculture. Journal of Sustainable Agriculture, 1, 19-42.

Sairam, R.K. 1994. Effect of moisture stress on physiological activities of two contrasting wheat genotypes. Indian Journal Experiments Biologic, 32, 584592.

Sajid, M.; Ullah, I.; Rab, A.; Shah, S. T.; Wahid F.; Ahmad, N.; Ahmad, I.; Ali, A.; Bibi, A. F. and Ahmad, M. 2020. Foliar application of calcium improves growth, yield and quality of tomato cultivars. Pure Appl. Biol., 9(1):10-19, http://dx.doi.org/10.19045/bspab.2020.90 $\underline{002}$

Sayed, R. A., Ibrahim, M. A. and Solaiman, B. M. 2007. Response of 'Valencia' orange trees to foliar and soil application of humic acids under new reclaimed land conditions. In: The Third Conference of Sustainable Agricultural Development. Faculty of Agriculture, Fayoum University, Egypt. 259-274.

Stevenson F.J., Lanath, F.A and Brar, M.S. 1993. Stability constants of $\mathrm{Cu}$ (II)humate complexes: comparison of select models. Soil Science. 155 (2): 77-91.

Taha S. S. and Osman A. Sh. 2018. Influence of potassium humate on biochemical and agronomic attributes of bean plants grown on saline soil. The Journal of Horticultural Science \& Biotechnology. 93 (5): $545 \quad$ - 554. https://doi.org/10.1080/14620316.2017.14 16960

Taiz, L.: Zeiger E.; Møller, I. M. and Murphy, A. 2015. Plant physiology and
2017. Effect of Foliar Nutrition of Different Sources and Levels of Calcium Fertilizer on Nutrient Content and Uptake by Tomato. International Journal of Current Microbiology and Applied Sciences. 6 (12): 1030-1036. https://doi.org/10.20546/ijcmas.2017.612. 115

Türkmen ö., Dursun, A., Turan, M. and Erdinc, Ç. 2004. Calcium and humic acid affect seed germination, growth, and nutrient content of tomato (Lycopersicon esculentum L.) seedlings under saline soil conditions. Acta Agriculturae Scandinavica, Section B, Soil and Plant Science, 54: 168-174.

Upadhyaya, H.; Begum, L.; Dey, B.; Nath, P. K. and Panda, S. 2017. Impact of Calcium Phosphate Nanoparticles on Rice Plant. Journal of Plant Science and Phytopathology, 1: 1-10. DOI: 10.29328/journal.jpsp.1001001.

https://www.researchgate.net/publication/ 315115591

Valdrighi, M. M., Pear, A., Agnolucci, M., Frassinetti, S., Lunardi, D. and Vallini, G. 1996. Effects of compost- derived humic acids on vegetable biomass production and microbial growth within a plant (Cichorium intybus)-soil system: a comparative study. Agriculture Ecosystems \& Environment, 58, 133-144.

Waraich, E.A.; Ahmad, Z.; Ahmad, R.; Saifullah, Ashraf, M.Y. 2015. Foliar applied phosphorous enhanced growth, chlorophyll contents, gas exchange attributes and PUE in wheat (Triticum aestivum L.), Journal of Plant Nutrition. 38(12): 1929-1943.

Wellburn, A. R. 1994. The spectral determination of chlorophyll-a and chlorophyll-b, as well as total carotinoids, using various solvents with spectrophotometers of different resolution. J. Plant Physiol. 144, 307-313.

Wilde, S. A., R. B. Corey, J.G. Lyer and G. K. Voight 1985. Soil and plant analysis 
for tree culture (3rd ed., pp. 93-106). New Delhi: Oxford and IBM Publishers.

Zapata, F. and Zaharah, A. R. 2002. Phosphate availability from phosphate rock and sewage sludge as influenced by addition of water soluble phosphate fertilizers, Nutrient Cycling in Agroecosyste.

\section{الملخص العربي \\ تأثير هيومات البوتاسيوم وفوسفات الكالسيوم على إنى إنتاج شتخلات الفلقل}

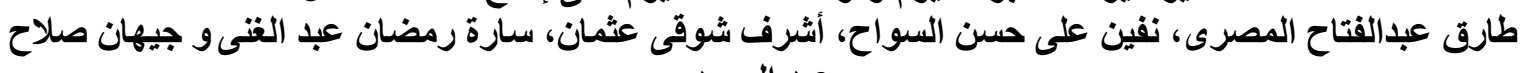
عبد الحميا

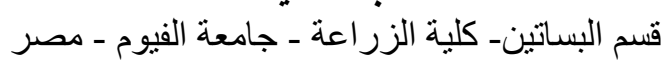

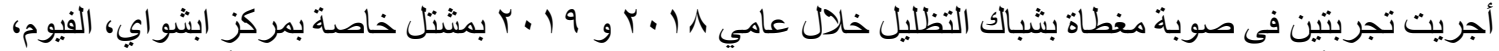

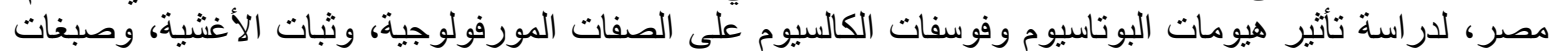

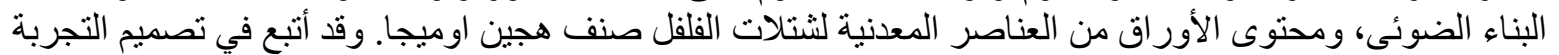

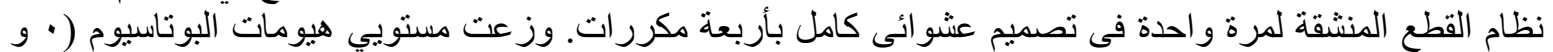

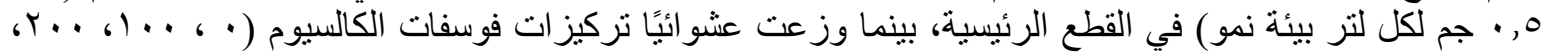

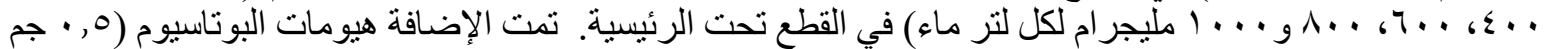

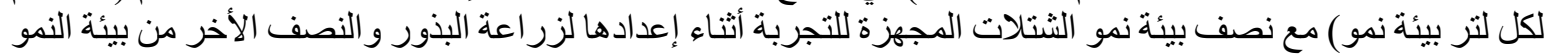

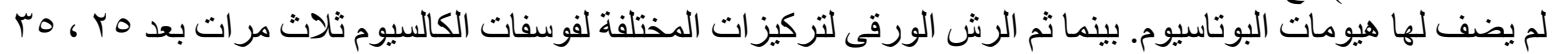

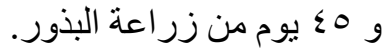

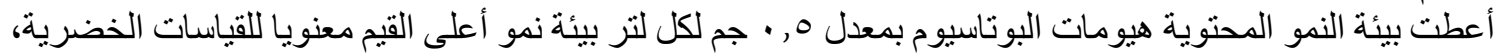

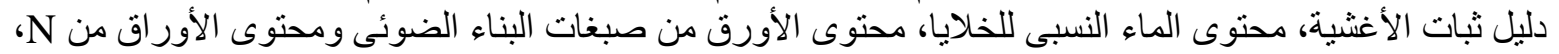

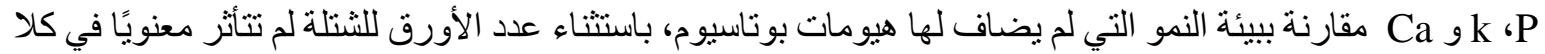

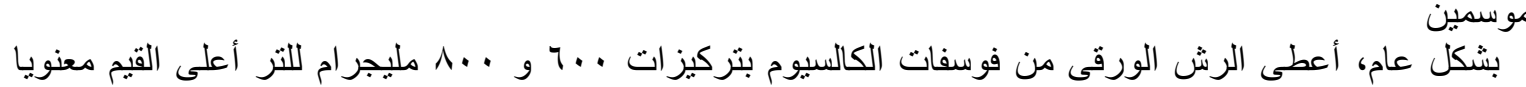

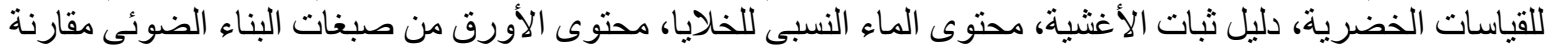

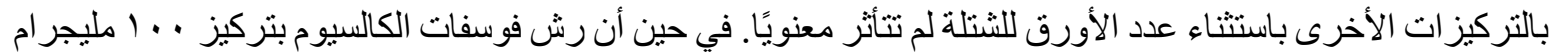

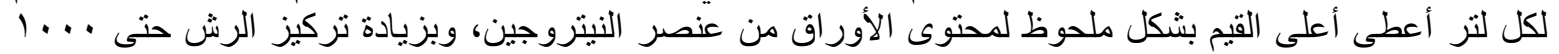

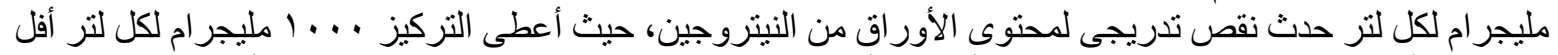

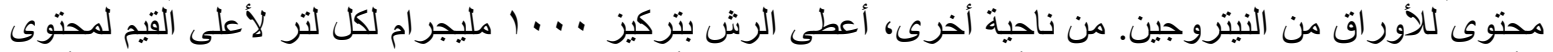

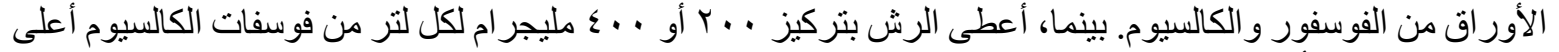

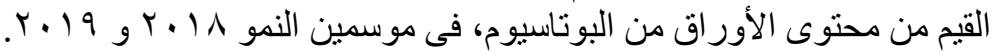

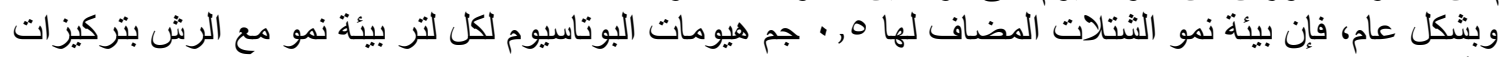

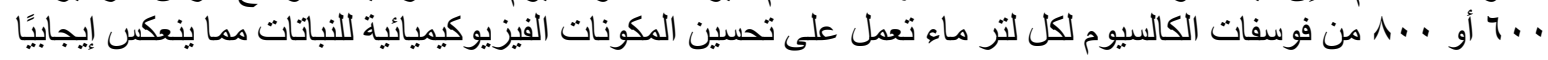
على نمو و إنتاج شتنات الفلفل. 